\title{
Are Bank Employees Satisfied with Perceived Leadership and Empowerment?
}

\author{
Shiraz Ahmed , Junaid Ansari $^{* *}$, Yamna Waqas Khan ${ }^{* * *}$, and \\ Muhammad Sufyan Ramish ${ }^{* * * *}$
}

\begin{abstract}
One of the reasons affecting job satisfaction is the leadership style that engages the employees on a daily basis. Although perceived leadership has been studied well in the past, but there are fewer studies focusing on the mediating effect of employee empowerment. The key objective of this research is to study the relationship of perceived leadership, employee empowerment and job satisfaction of the employees, and also to study the mediating role of employee empowerment on the relationship between perceived leadership, and job satisfaction of the employee. A sample of 200 professionals from different banks was selected for the purpose of this study. Moreover, the Smart PLS 3.0 software was used to analyze whether the model was fit by referring to the PLS-SEM. The results of this study revealed that the independent variable (perceived Leadership) has a significant and positive influence on job satisfaction. All the hypotheses were accepted, and there were none that could be rejected after the results were revealed. The study proves that a partial mediating effect of employee empowerment exists between perceived leadership and job satisfaction. This study can help managers in designing the right strategies for retaining their employees by empowering them according to the boundaries set by their organizations. The results can help organizations to identify the potential reasons for job satisfaction, which will eventually lead to higher productivity and profitability.
\end{abstract}

Keywords: Perceived leadership, employee empowerment, job satisfaction, mediating effect of empowerment, and Pakistani banks.

JEL classification: J2, M10, M12.

\footnotetext{
* Assistant Professor, Institute of Business Management (IoBM), Karachi, Pakistan.

** PhD Scholar, Institute of Business Management (IoBM), Karachi, Pakistan.

*** PhD Scholar, Institute of Business Management (IoBM), Karachi, Pakistan.

**** PhD Scholar, Institute of Business Management (IoBM), Karachi, Pakistan.
} 


\section{Introduction}

Over the years, the business environment has changed rapidly around the globe. Increasing competition calls for organizations to allocate their resources in the most efficient way in order to gain a competitive edge over others in the market. Just as there has been a dynamic change in other sectors, the banking sector of Pakistan also requires development and research, so that it can achieve outstanding growth (Shahid, Rehman, Niazi \& Raoof, 2010). Looking back at the history, it can be observed that the banking sector has continuously grown for almost ten years. Financial institutions such as banks face day to day challenges, so as to endure in this strong, competitive business environment which is paving its way into Pakistan as well. It must be noted that in order to sustain in the market, banks face the challenge of providing high-quality products/services that give the best value for money and are economical in terms of prices (Sohail, Iqbal, Tariq \& Mumtaz, 2013). If one observes keenly, the employees of a bank are mostly engaged in public dealing and relationship management. If these employees are happy and satisfied with their job, they will keep the customers satisfied otherwise, their attitudes will reflect in their demeanor towards the customers (Kundu, Kumar \& Gahlawat, 2019). Traditionally, banks tend to invest in training their employees because well-trained and skilled employees are one of the main priorities of the banking system. However, employees are constantly inclined towards better opportunities in the financial sector, and switch their jobs very frequently, which has become a critical issue in such organizations (Saeed et al., 2013). Hence, there is a need to retain valuable employees by empowering them so that job satisfaction and retention can increase.

The reason for selecting the banking industry of Pakistan for this research is that this sector is facing continuous disruptions in its payment systems. These disruptions include the worsening economic conditions, political instability, and energy crises which affect the banking sector in a negative way. These factors become a cause of additional stress for employees, due to which their job satisfaction is decreasing with each passing day (Saeed et al., 2013). Pakistan is quite a diverse country, and is a motherland to the inhabitants of different cultures, traditions, religions, and economies. The reasons of motivation, and satisfaction of the people of Pakistani are different from the other countries of the world. For this very reason, the studies conducted in other countries on employee empowerment, leadership and job satisfaction cannot be fully applied to the Pakistani context. Several times, the organizational culture does not allow employees to make decisions on their own (Gokhan \& Kuzey, 2019), 
and this is why they are bound to follow the commands of their superiors. Therefore, it is a need of the time to study the effect of perceived leadership on the level of job satisfaction of employees, in relation to the effect of employee empowerment.

In previous studies, employee empowerment is well-defined in several ways, but generally, it is a procedure of giving control to employees, so as to manage their work, to openly share their ideas about work, and to improve the organizational processes (Baird \& Wang, 2010; Greasley et al., 2005). Empowered employees are considered to be more committed, loyal and hardworking. They serve as strong representatives of their organizations. According to research on employee empowerment and job performance, it is evident that if employees feel empowered and contented with their job roles and responsibilities, their work performance and productivity increases. This eventually benefits the organization, and is a win-win situation for all the stakeholders involved in the organization (Greasley et al., 2005; Singh \& Singh, 2019). One of the main reasons behind decreasing job satisfaction among the bank employees is due to the leadership role that engages the employees. Although the perceived leadership has been studied, there are only a few studies which analyze the mediating effect of employee empowerment, on job satisfaction. There are other factors as well which may affect the job satisfaction. These mainly include teamwork, work environment, job autonomy, nature of the job, and the behavior of the management (Danish \& Usman, 2010; Hanaysha \& Tahir, 2016). However, this study has specifically considered the perceived leadership in order to predict the employees' job satisfaction, based on the theoretical ground of the empowerment theory. The empowerment theory suggests that leaders have a capacity to exert control, and influence organizational decisions that affect employee job satisfaction (Kundu et al., 2019; Qing, Asif, Hussain \& Jameel, 2019; Rajotte, 1996). When employees have a good interpersonal relationship with their managers/leaders, they become more satisfied with their jobs. Hence, effective leaders are the main reason behind the satisfaction of employees (Michael Ba, 2015; Pigg, 2002).

Another significant contribution of this study is to highlight the mediating role of employee empowerment in the relationship between leadership and employee job satisfaction. The theory of empowerment also suggests that the level of employee job satisfaction increase when employees get empowered and encouraged by their leaders/managers. Moreover, the empowerment theory also emphasizes that empowerment holds a central position in reciprocating the influence of employees on their leaders. In today's contemporary era, employees truly expect, and demand 
a sense of autonomy, competence, and regulation authority from their leaders. Once employees perceive effective leadership, they feel psychologically empowered, and become more committed and satisfied with their organizations and role in the company (Elnaga \& Imran, 2014; Rajotte, 1996; Salek \& Khoeini, 2016).

Past studies suggest a significant and strong relationship between job satisfaction and leadership. Both variables have been studied numerous times in the past (Bushra, Usman, \& Naveed, 2011; Saleem, 2015), but there is a dearth of research that explains that employee empowerment can perhaps play a mediating role in the leadership and job satisfaction of employees. Moreover, the banking industry in Pakistan is less studied with respect to such relationships. Hence, the research questions raised in this study are: (i) What is the role of Perceived leadership affecting the job satisfaction of the bank's employees? (ii) What is the role of employee empowerment in the relationship between perceived leadership and job satisfaction?

The main reason for carrying out this research is to further understand the role of the management and leadership, especially when it comes to motivating the workforce to perform well, specifically in the banking industry of Pakistan. High turnover can be observed due to the rigidity of the rules that define the professional commitments of employees, which often seep into their personal lives as well. Several studies suggest that in instances where employees seem dissatisfied with their jobs, the next probable result of this sentiment would be the low work performance, absenteeism, high turnover intentions and other behaviors affecting the overall productivity of organizations (Danish \& Usman, 2010; Saeed et al., 2013). Hence, the key objectives of this research include the identification of the effect of perceived leadership on the employees' job satisfaction at the bank, and the identification of the mediating effect of employee empowerment in relationship between the perceived leadership and the job satisfaction of the banks' employees.

\section{Literature Review and Hypotheses Development}

It is noticeable, that a lot of research work has been carried out in order to investigate the phenomenon of job satisfaction, especially over the last 50 years, with respect to the attitude of people within the organization. It is a complex subject and has attracted many researchers to shed light over the issues that surround it (Loi, Yang \& Diefendorff, 2009). An employee's job satisfaction is not only good for the organization, but is also 
important for the organization's culture (Saeed et al., 2013). Job satisfaction, leadership, and empowerment have been studied widely in different domains and contexts (Qing et al., 2019; Shaista, Muhammad, Muhammad \& Syed, 2019; Yong, Peiwei, Jingying \& Hui, 2019) however, the mediating effect of employee empowerment and perceived leadership with the job satisfaction of the employees is an area of study that has not been studied in depth.

\subsection{Theoretical Underpinnings}

The theoretical background of this study is based on the concepts put forth by the two-factor theory of satisfaction (Herzberg, 1959). This theory helps in the identification of several factors which affect the job satisfaction of employees. Herzberg (1959) divided these factors into two categories of motivational factors; extrinsic and intrinsic factors. The extrinsic factors, also known as the hygiene factors, are not directly linked with the job design. The extrinsic factors include pay, supervision, work environment, and the relationships enjoyed with an employee's peers and supervisors. The absence of these extrinsic factors is the main reason that leads to employee dissatisfaction (Dartey-Baah \& Amoako, 2011). On the other hand, there are intrinsic factors (Ewen, Smith, Hulin \& Locke, 1966), which are directly related to the job. The Intrinsic factors may include nature of the work, promotion, recognition, achievement, communication, career growth, and responsibilities. These factors are the main motivators influencing the job satisfaction level of the employees. On the basis of the theoretical underpinnings, given below is the discussion about job satisfaction, perceived leadership, and employee empowerment, as a series of three different constructs used in this study:

\subsubsection{Job Satisfaction}

In general, the employees' satisfaction is a factor that is used to mention people's psychological situations, when their needs have been met. The satisfaction of employees is one of the important factors, which links the organizational demands with the needs of employees, and hence, also enhances their happiness (Crawford, Lepine \& Rich, 2010). Scholars suggested that the job satisfaction of an employee lays the whole emphasis on the fact whether "the rewards received, actually meet or exceed the received equitable level of rewards" (Porter \& Lawler, 1968, p.31). Therefore, it would be appropriate to say that job satisfaction is a combination of different expectations of employees, such as a handsome pay, autonomy, career growth, etc. These combinations, however, may be different for different individuals, that too in different situations. The other 
dimensions of job satisfaction reflect its positivity in terms of various factors, such as, for example, the positive emotions associated with the job. It is a pleasurable state that is achieved because of the professionally sound experiences and appraisals on the job (Locke, 1976). Other scholars share the opinion that there is an emotional reaction that takes place in either liking or disliking the work experiences that one comes face to face with, and such emotional feelings can impact the employees' social behavior (Buitendach, 2005). According to Rad and Yarmohammadian (2006), the greater the difference between work experience of employees and their level of expectations from their job, the greater are the chances of dissatisfaction associated with their respective job roles/positions. Another orientation of job satisfaction is the combination of different work attitudes and work statuses. These work attitudes drive the behavior of the employees during their work hours. Positive attitudes reflect higher job satisfaction, and negative attitudes reflect the signs of job dissatisfaction (Armstrong, 2006; Yong et al., 2019).

\subsubsection{Perceived Leadership}

In the field of social sciences, it is important to note that 'Leadership' is one of the most extensively studied subjects. It has gained prominence almost everywhere, from the field of education to social organizations, as well as from politics to business. It is one of the critical components affecting an employee's job satisfaction, because of its role in creating the good/bad perceptions of employees at the workplace (Macey \& Schneider, 2008; Wang \& Walumbwa, 2007). Leadership in organizations is actually a relationship of the management with their subordinates. The leadership of a boss or a leader is not separated from the perception of employees, as the leadership style is crucial for the empowerment, encouragement, and engagement of employees (Attridge, 2009). It is believed by several scholars that a supervisor can enhance an employee's level of engagement at work. Distance between the employees and their supervisors affects the perceptions, and this, as a result, have an outcome of positive or negative performance and attitudes (Avolio, Zhu, Koh \& Bhatia, 2004). A better or more acceptible (according to the organizational culture) leadership style of supervisors predicts better outcomes for an organization. Moreover, better and more effective leadership of the supervisors affect the employees' job satisfaction, turnover intention, empowerment and performance (Gerstner \& Day, 1997). If a supervisor acts as a leader with his behavior, and leads by exemplary actions, he may strongly influence the employees of an organization. 


\subsubsection{Employee Empowerment}

Employee empowerment is not a new construct to be studied in the Pakistani society. This construct was taken as an independent variable in most of the studies that were conducted earlier. In Pakistan, employees empowered as much as they should be, therefore, their job satisfaction may decrease due to the mediating effect of empowerment (Elnaga \& Imran, 2014; Qing et al., 2019). Empowerment is important, as well as beneficial for the organization as well as its employees. Organizations must provide a culture where self-managed and accountable teams can emerge. Employees who feel empowered within an organization, turn out to be more effective in their work, as they see themselves as individuals who are innovative and highly competitive (Quinn \& Spreitzer, 1997). When organizations empower their employees, their efficiencies tend to increase. This is because employees perceive this empowerment as a constructive initiative from their employer, and feel that they are in total control of their job designations and performance. They start feeling more connected to their employer, as their commitment and loyalty gets aligned with the vision of their organization (Shaista et al., 2019; Sternberg, 1992). When managers empower their employees, such employees have a chance to develop their self-worth, which helps these managers ignore negative emotions such as helplessness and powerlessness within the given role that they are performing within the organization. Empowered employees become intrinsically excited to work, and become more energetic in performing up to the mark (Fernandez \& Moldogaziev, 2013).

\subsection{Effect of Perceived Leadership on Job Satisfaction}

When we talk about increasing the level of productivity of employees in an organization, the concept of job satisfaction holds critical value. Not only for employees but for the overall benefit to the organization, managers need to lay great emphasis on ways to increase employees' satisfaction level at their respective workplaces (Ahmad \& Yekta, 2010; Danish \& Usman, 2010). So it is necessary to gain an understanding of an organization's leadership, and how its followers think about their leaders because the previous studies have suggested that perceived leadership may positively affect the employees' level of job satisfaction. Several studies have already been conducted in different countries, pointing towards a positive relationship between employees' job satisfaction and the role of a supervisor as a leader in an organization (Ahmad \& Yekta, 2010; Qing et al., 2019). Leading organizations aim to collaborate more with their employees and make them "partners in the 
businesses". The main objective behind this collaboration is to develop a sense of mutual trust among the employees and the organization. When employees feel that they are being valued by their employer, only then they would deliver that exponential performance, which organizations seek in their employees, and this is exactly what benefits the corporation in the long run (Cabrera \& Cabrera, 2002; Shaista et al., 2019; Sternberg, 1992). On the basis of the past literature, the following hypotheses for this study is derived:

Hypothesis 1: Perceived leadership positively affects employees' job satisfaction.

\subsection{Mediating Effect of Employee Empowerment}

Previously, Employee Empowerment has been considered a mediating variable in several studies, for example, a research was conducted in the Netherlands which concluded that the psychological empowerment of a follower plays a mediating role between leadership types (Pieterse, van Knippenberg, Schippers \& Stam, 2010). As a mediating variable, Employee Empowerment was also used in a study that affected the job satisfaction of employees. Similarly, empowerment has also been used as a mediating variable in several other studies (Carless, 2004; Kundu et al., 2019; Qing et al., 2019). For example, in a study conducted previously, psychological empowerment was found as a mediating variable in the relationship between leadership and employee's attitude towards the job (Castro, Periñan \& Bueno, 2008), and it has also been taken as a mediating variable in the relationship between the independent variable i.e. leadership style, and the dependent variable i.e. organizational commitment (Avolio et al., 2004; Lee \& Kim, 2008). Furthermore, empowerment has also been taken as a mediating variable in a study which concluded that empowerment mediates the relationship between leadership and job satisfaction (Ugboro \& Obeng, 2000).

\subsection{Empowerment and Job Satisfaction}

Scholars have studied the relationship between employee empowerment and job satisfaction, and discovered that the dimensions of empowerment strongly influence job satisfaction. It has been observed that when employees find a similarity between their objectives and the goals of their particular organization, their capability of performing well becomes better by manyfold. Through research, it has been found that a positive relationship exists between empowerment and job satisfaction (Fulford \& 
Enz, 1995; Oluwaseun, 2016; Qing et al., 2019). Structural empowerment in organizations affects the employee's job strain, and psychological empowerment acts as a mediating variable between structural empowerment and job satisfaction (H. Laschinger, 2008; Pelit, Öztürk, \& Arslantürk, 2011). Another study revealed that the changes in psychological empowerment, and job satisfaction are directly affected by the perceived structural empowerment $(H$. K. S. Laschinger, Finegan, Shamian \& Wilk, 2004). Furthermore, a deeper investigation into the literature revealed that the employees' perception of empowerment is directly influenced by the perception they have of their work environment, and this empowerment, ultimately influences their level of job satisfaction. Many scholars studied this phenomenon and came to the conclusion that psychological empowerment, and job satisfaction are positively related, and a strong direct relationship exists between these two variables(H. K. S. Laschinger, Finegan \& Shamian, 2002; H. K. S. Laschinger et al., 2004).

\subsection{Empowerment and Perceived Leadership}

This study has taken perceived leadership as an independent variable, so as to study its effect on job satisfaction, whereas empowerment has been considered a mediating variable in this relationship. Previous researches have also considered empowerment as a mediating variable between perceived leadership and job satisfaction (Kundu et al., 2019; Ugboro \& Obeng, 2000). The empowerment theory has been referred to in several studies, in order to investigate the relationship between leadership and empowerment (H. K. S. Laschinger et al., 2004; Rajotte, 1996). Empowerment has widely been researched with respect to perceived leadership, and different styles of leadership. One of the studies has highlighted the critical role of empowerment in such organizations, where management styles vary (Michael $\mathrm{Ba}, 2015)$. The role of perceived leadership and employee outcome (empowerment) has also been discussed by measuring job satisfaction in the chemical industry (Nel, Stander \& Latif, 2015). On the basis of the previous studies and discussion, the following hypotheses are derived:

Hypothesis 2: Employee empowerment mediates the relationship between perceived leadership and job satisfaction.

Hypothesis 2a: Perceived leadership positively affects employee empowerment 
Hypothesis 2b: Employee empowerment positively affects job satisfaction.

\subsection{Conceptual Framework}

The literature above considers perceived leadership as an independent variable, employee empowerment as a mediator, and job satisfaction as a dependent variable. On the basis of the theoretical underpinnings, this study derives some of its hypotheses which are related to the empowerment, perceived leadership and job satisfaction. These constructs have been discessed in several studies which have proposed models which show that job satisfaction can be directly predicted by employee empowerment and perceived leadership (Barroso Castro, Villegas Periñan \& Casillas Bueno, 2008; Dickson, Lorenz \& Illinoisan, 2009; Kundu et al., 2019; Oluwaseun, 2016). On the basis of the discussion mentioned above, the conceptual framework of this study was develped using three variables; job satisfaction, empowerment, and perceived leadership as shown in Figure 1.

Figure 1: Conceptual framework

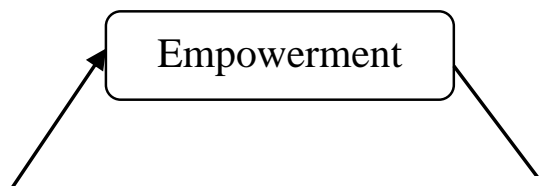

$\mathrm{H} 2$ (a)

$\mathrm{H} 2$ (b)

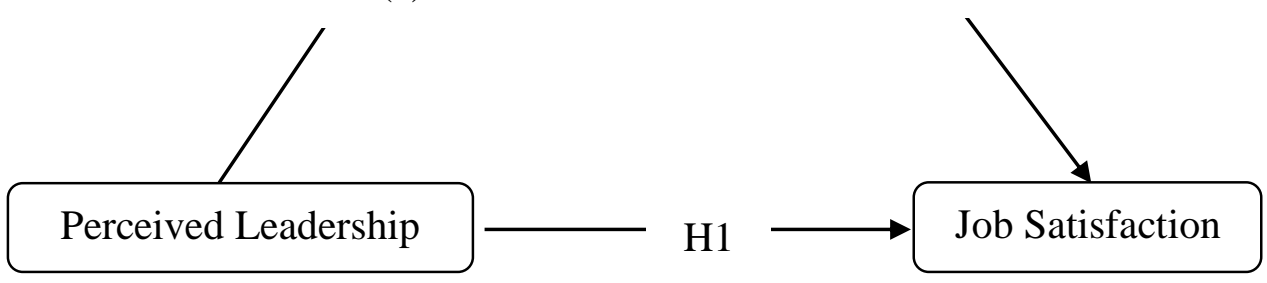

\section{Methodology}

The methodology of this study includes its research design, sampling technique, sample size, instruments used for data collection, reliability, validity and other strategies that are adopted for testing of the constructed hypotheses. This is a quantitative study, for which the empirical testing of the hypotheses is deemed appropriate (Fernandez \& Moldogaziev, 2013). To collect the data, a representative sample of the population is required, as it is impossible to get responses from a large group, which 
typically constitutes of the targeted population of the study (Bechwati \& Baalbaki, 2011). The population selected for this research includes all the banking sector employees working in any commercial bank of Pakistan, which number to around 162,629, as mentioned in the annual report of state bank of Pakistan, published in 2016. There are different opinions that have been presented when it comes to the selection of the sample size. Sekaran (2000) suggests having at least 30 respondents for each variable, in order to conduct a multivariate analysis. Similarly, various scholars also suggest that a sample size of 250 firms is one that should be deemed to be appropriate for a study, whereas some scholars suggest selecting a sample size on the basis of a confidence interval and confidence level (Hair, Black, Babin \& Anderson, 2006). In this research study, we have used the 'convenience' sampling technique, in order to collect data from the targeted respondents. This technique enables a researcher to select the respondents according to their ease, however, the sample should represent a subset of the selected population (Sekaran, 2000). After the collection of data, tests, which are statistical in nature, were conducted to empirically evaluate the relevant data. For this purpose, the descriptive test, reliability, and validity tests were conducted using SPSS 17 and Smart PLS 3.0.

\subsection{Instrument Development}

The instrument developed on the basis of the three constructs, perceived leadership (11 items), and job satisfaction ( 7 items) were adopted from Almandeel (2014), and employee empowerment (5 items) was adopted from Oluwaseun (2016). In total, there were 27 items in the questionnaire, including the demographics, and 22 items were representing the selected constructs. The scale used to get the questionnaires filled is a 5-point Likert scale, in which 5 stands for 'extremely disagree', and 1 represents 'Strongly Agree'. The adopted instrument for this research has already established the reliability, which means that the Cronbach alpha is greater than 0.7 , which is on the positive side (Sekaran, 2000). The questionnaire was divided into 4 parts i.e. demographics, perceived leadership, empowerment and job satisfaction.

\section{Results}

According to the demographics depicted in this study, the marital status of the respondents is shown as 128 (64 percent) of respondents who were single and 72 (36 percent) were married. All of these respondents belong to the banking sector of Pakistan. In terms of education, the respondents having graduate degree were $120(60 \%)$ in number, and 
other respondents amounted to $80(40 \%)$ people, who had at least a postgraduate degree.

\subsection{Descriptive Statistics}

Typically, the regression analysis cannot be conducted on the data if it does not follow the normal distribution. To ascertain the univariate normality of the collected data, the descriptive analysis is resorted to. If the ranges of skewness and kurtosis are between -2 and +2 , the data is considered as normal data (George \& Mallery, 2003). Table 1 depicts the overall results of descriptive statistical analysis, which includes the sample mean, standard deviation, kurtosis, and skewness.

Table 1: Descriptive Statistics and Reliability Analysis

\begin{tabular}{lccccc}
\hline & Mean & Std. Dev. Skewness Kurtosis & $\begin{array}{c}\text { Cronbach's } \\
\text { Alpha }\end{array}$ \\
\hline Perceived Leadership & 3.84 & 3.84 & -0.78 & 0.51 & 0.78 \\
Employee Empowerment & 3.72 & 0.75 & -0.60 & 0.14 & 0.71 \\
Job Satsfaction & 3.59 & 0.76 & -0.68 & 0.79 & 0.82 \\
\hline
\end{tabular}

\subsection{Reliability of the Constructs}

The internal consistency and closely related items in a normally distributed data are checked by the Cronbach's alpha value, which ensures that the data is reliable, if the value of alpha is greater than 0.7. Although, the instrument used in this study was taken from a previously conducted research, it is still required to conduct the reliability test again due to the variation in the culture, and the respondents' level of understanding (Santos, 1999). Therefore, the reliability test by using the Cronbach alpha was conducted for the purpose of this study, and the summary of the results is presented in Table 1.

The Table 1 above shows that the reliability of job satisfaction towards perceived leadership is highest $(\alpha=.82, \mathrm{M}=3.59, \mathrm{SD}=0.76)$ while the reliability of employee empowerment is the lowest $(\alpha=.71, \mathrm{M}=3.72$, $\mathrm{SD}=0.75$ ). The overall reliability (i.e. Cronbach Alpha) value of the instrument taken in this study is 0.83 , which includes both the independent and dependent variables. 


\subsection{Correlation Analysis}

Whether a relationship between variables exists or not is usually checked by the correlation analysis. The test of correlation analysis ensures the multi-collinearity among variables, and is a prerequisite in order to conduct the regression analysis. Scholars suggested that correlation amongst the constructs should lie between 0.20 and 0.90 , otherwise the item should be discarded. If the correlation coefficient is greater than 0.90, the items can be also merged together (Bryman \& Bell, 2007). The correlation analysis results are presented in Table 3.

\section{Table 2: Correlation Results}

\begin{tabular}{lccccc}
\hline & PL & EE & JS & Age & Marital \\
\hline Perceived Leadership & 1 & & & & \\
Empowerment & $0.30^{*}$ & 1 & & & \\
Job Satisfaction & $0.46^{*}$ & $0.44^{*}$ & 1 & & \\
Age & $0.47^{*}$ & $0.25^{*}$ & $0.27^{*}$ & 1 & \\
Marital & $0.23^{*}$ & $0.21^{*}$ & $0.29^{*}$ & $0.21^{*}$ & 1 \\
Education & $0.35^{*}$ & $0.40^{*}$ & $0.47^{*}$ & $0.45^{*}$ & $0.20^{*}$ \\
\hline
\end{tabular}

Note: *Values are significant at $\mathrm{p}$-level $<0.05$

Table 3 shows that the relationship between variables is distinguishing and unique, as perceived leadership has a positive correlation with job satisfaction $(\mathrm{r}=.46)$, whereas employee empowerment shows a weak correlation ( $\mathrm{r}=.30)$ with job satisfaction. The values shown in the bold font represent the Cronbach's Alpha values, which were reascertained as this research is conducted in a different country and culture. All values of the reliability analysis satisfy the condition of alpha $>0.7$ (Hair, Black, Babin, \& Anderson, 2009).

\subsection{Construct Validity}

When constructs are adopted in any research, their validity must be ensured due to the variance which might occur because of cultural and demographical differences. The constructs used in this study were previously used in different studies as well, so administering them according to the Pakistani environment may affect the results. Therefore, to maintain the uniformity of the study, it was required to ascertain the 
validity of the respondents' data. Construct validity is determined by conducting the tests of "convergent validity" and "discriminant validity" (Fornell \& Larcker, 1981). The test of convergent validity can be ascertained by checking the AVE (average variance explained), the values of which must be greater than 0.40. Since all the values of AVE in this research are greater than 0.4 , it means that the data fulfills the requirements of the convergent validity (Hair et al., 2009).

\subsection{Discriminant Validity Test}

The uniqueness of the correlated variables is identified by conducting the test of discriminant validity. The discriminant validity test ascertains that the variables are distinct in nature (Hair et al., 2009). The process of conducting discriminant validity test includes the calculation of the square root of total variance explained, which must be greater than the value of each pair of correlation (Ansari, Khalid, Jalees \& Ramish, 2017; Fornell \& Larcker, 1981). The respondents' data in this study fulfills the requirement of discriminant validity, as summarized in Table 4.

Table 3: Discriminant Validity

\begin{tabular}{lccc}
\hline & PL & Emp & JS \\
\hline Perceived Leadership & 0.83 & & \\
Empowerment & 0.09 & 0.88 & \\
Job Satisfaction & 0.21 & 0.19 & 0.81 \\
\hline
\end{tabular}

\subsection{Structural Equation Modeling and Mediation Analysis}

As this is a cross-sectional data analysis, Harmon's Single Factor test is recommended to check the common method bias. The specified test recommends that a single factor should explain more than $40 \%$ of the variance, which reduces the chances of the common method bias (CMB), hence this study fulfills the requirement of CMB (Ali, 2016; Reams, 2013).

The overall model was tested through the PLS-SEM analysis, using the Smart PLS 3.0 software. The Confirmatory Factor Analysis CFA was carried on the PLS-SEM in order to test the model. All factor loadings were found significant and above the acceptance criteria i.e. 0.5. The values of reliability and validity analyses were also found to be positive in nature i.e. 
composite reliability $>0.7, \mathrm{AVE}>0.5$, and Cronbach's alpha $>0.7$. Moreover, the multicollinearity test indicates that all VIFs $>=1$, hence no chances of multicollinearity were found (Ansari et al., 2017; Fornell \& Larcker, 1981; Hair et al., 2006). The model fit indices show the result that NFI $=0.81$ and $\mathrm{SRMR}=0.08$. The approximate fit indices include the Standardized Root Mean Square Residual (SRMR), which is recommended to be less than 0.08, however, the cutoff value is 0.1 (Henseler et al., 2014). Hence the model represents an acceptable goodness of fit.

\section{Table 4: SEM Coefficients and Specific Indirect Effect of Perceived Leadership on Job Satisfaction}

\begin{tabular}{lccc}
\hline & Coefficient & t-Statistics & Hypothesis \\
\hline Emp $\rightarrow$ JS & 0.43 & 5.87 & Supported \\
PL $\rightarrow$ Emp & 0.42 & 5.74 & Supported \\
PL $\rightarrow$ JS & 0.28 & 3.57 & Supported \\
PL $\rightarrow$ Emp $\rightarrow$ JS & 0.17 & 4.24 & Supported \\
\hline
\end{tabular}

The results of the test indicate that there is a significant effect of empowerment on job satisfaction, perceived leadership on empowerment, and perceived leadership on job satisfaction (See Figure 2). Therefore, empowerment can be considered as a mediating factor between perceived leadership and job satisfaction. For testing the mediation analysis, the bootstrapping method with subsamples of 2000 is used in this research. After conducting the bootstrapping test, it was found that the specific indirect effect of perceived leadership on job satisfaction is significant, but the effect has been reduced from 0.28 to 0.17 (See Table 5), which shows that a partial mediation of Empowerment exists between perceived leadership and job satisfaction (Baron \& Kenny, 1986).

It is found that empowerment (mediator) and perceived leadership (predictor), both, are creating a positive effect on the dependent variable i.e. job satisfaction, as identified in Table 5. The regression analysis indicates that the overall model is significant, and the predictor variables i.e. empowerment and perceived leadership, significantly affect the dependent variable i.e. Job satisfaction explains $34.8 \%$ of the variance $\left(\mathrm{R}^{2}=\right.$ $0.259, \mathrm{~F}(2,197)=25.9, \mathrm{p}<.05)$. These results represent a larger, more expansive effect, as suggested by Cohen (1988). 
Figure 2: Structural equation modeling using Smart PLS

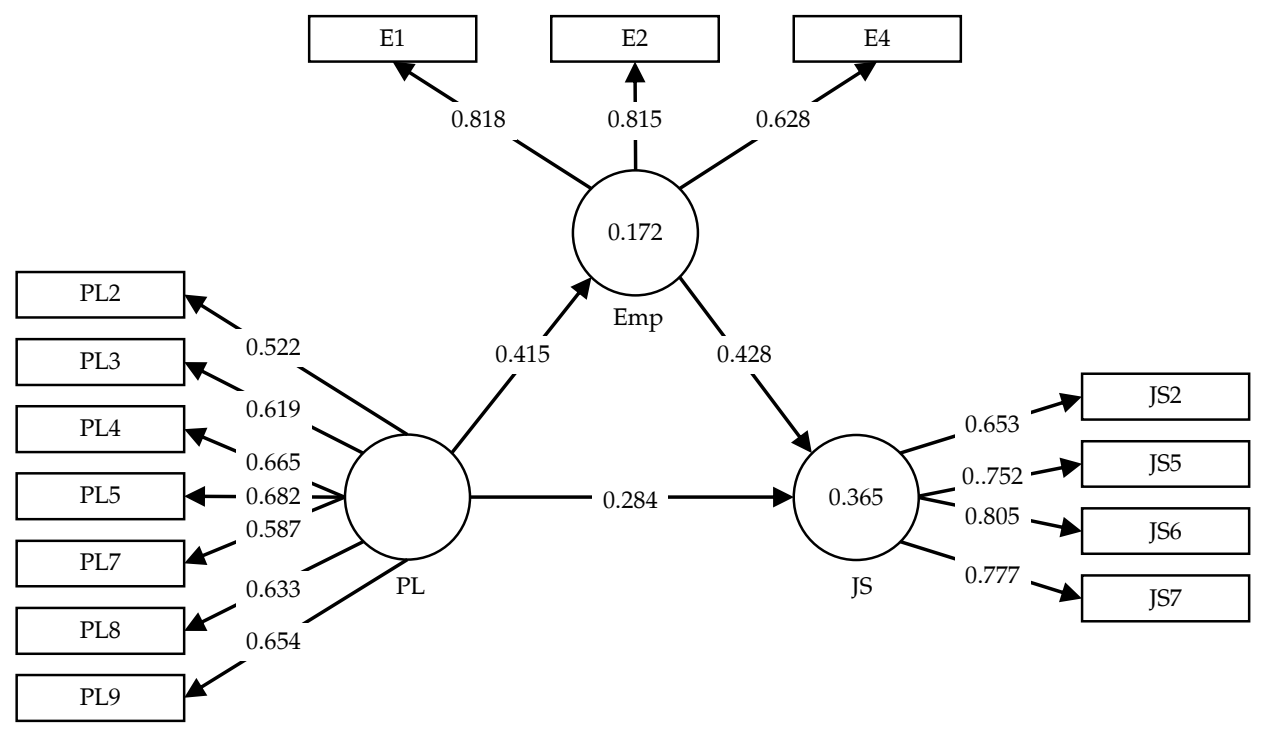

\section{Discussion and Conclusions}

Through this study, we tried to explain the significance of perceived leadership, and the effect it has on the employees' job satisfaction. Results of both the selected hypotheses of this study were found to be consistent with the results observed in previous studies. To further explain the substantiation of the hypotheses, in connection to the previous studies, the specified findings of this study are discussed below:

\subsection{Hypothesis 1}

Hypothesis 1 was stating the effect of perceived leadership on the employees' job satisfaction. The selected hypothesis was substantiated in this study (Refer to, Table 5). The results reveal that if the level of perceived leadership of the supervisors/bosses increases, then it will positively affect the employees' job satisfaction. This outcome is also consistent with the revelations of the previous studies, which state that the lesser the hierarchical distance between the followers and leaders, the better would be the performance of the employees (Avolio et al., 2004; Fernandez \& Moldogaziev, 2013; Hanaysha \& Tahir, 2016). 


\subsection{Hypothesis 2}

Our analysis shows that a partially mediating and significant effect of employee empowerment exists in the relationship between perceived leadership, and the employees' job satisfaction. Results show that the second hypothesis is also substantiated. This means that employee empowerment, indeed, has a mediating effect in the relationship between the employees' perceived leadership, and the employees' job satisfaction (Refer to Table 5). This answers the second research question as well. Furthermore, results are also consistent with the previous studies that were conducted on this subject (Qing et al., 2019). Another study states that "Empowered employees see themselves as more productive in their work, with an increase in the level of commitment, and enhanced ability to try new things at work" (Quinn \& Spreitzer, 1997, p.42).

This research, along with the previous literature, will contribute to the work coined in by other researchers. This is because employee empowerment, as a mediating variable, has been found in a few studies. This is especially true in the context of the banking sector where perceived leadership significantly affects empowerment by increasing the satisfaction of employees.

The concept of empowerment does not mean, specifically in the context of this study, that the employees and staff are given extraordinary power, rather, it involves a way of defining oneself, along with a capacity to complete the tasks in the given time and environmental conditions. Organizations having a strong competitive environment, such as banks, should focus on their employees, as they are the most important resource they possess, especially in a country like Pakistan. All organizations should empower their employees, along with improving their rules and policies for empowering the current and future leaders as well. Identification of the criteria, and a plan to practically implement the same is critical for an organization in order to empower its employees.

\subsection{Implication for Managers/Policy Makers}

Several studies in the past studied the different factors affecting job satisfaction in the Pakistani culture, but the mediating effect of empowerment is less studied in the Pakistani context. Managers, supervisors and human 
resource officials should consider this study as an important guide to motivate their employees by empowering them, and should also continue to assess the perceived leadership of the supervisors, leaders and management. The results of this study suggest that Pakistani banks should empower their human resources because the leadership effect is partially mediated by empowerment. Managers in a bank may not be considered good and effective leaders, but if they are empowered in the appropriate manner, they can run their operations smoothly because of higher job satisfaction. Continuous assessment will help banking institutions to improve their processes, and to achieve their goals in a timely fashion as the employees will be happy with their current jobs. Training and development activities are required in order to guide the supervisors and managers on how to treat their subordinates in a professional manner. Empowerment needs to be supported at all levels, and it should be reflected within the employees and the values that they reflect.

\subsection{Research Limitations and Scope for Future Research}

This study focuses on the employees of banks, within the geographic boundary of a metropolitan city. Not all variables, that may affect the perceived leadership and employee empowerment, were considered in this research. Moreover, psychological factors affecting the responses of the respondents were not considered in this research. It must also be noted that other dimensions of perceived leadership, job satisfaction, and employee empowerment still need further investigation. Also, the leadership styles were not considered in this study, which can be investigated in future research. Future research in this area can help to gain a deeper understanding of the effects of leadership, and empowerment, on job satisfaction. Moreover, there could be other factors which may be related to the leadership and empowerment of professionals within an organization. For instance, future studies can include demographics as mediators or moderators, in order to explain those relationships that have been examined in this research. 


\section{References}

Ahmad, Z. A., \& Yekta, Z. A. (2010). Relationship between perceived organizational support, leadership behavior, and job satisfaction: An empirical study in Iran. Intangible Capital, 6(2), 162-184.

Ali, F. (2016). Hotel website quality, perceived flow, customer satisfaction and purchase intention. Journal of Hospitality and Tourism Technology, 7(2), 213-228.

Almandeel, S. M. (2014). The impact of employees personality traits in perceiving leadership styles and organizational attitude in Saudi Banking context (Doctoral Thesis). University of Portsmouth.

Ansari, J., Khalid, F., Jalees, D. T., \& Ramish, M. S. (2017). Consumer's Attitude towards Ramadan Advertising. South Asian Journal of Management Sciences, 11(1), 15-31.

Armstrong, M. (2006). A Handbook of Human Resource Management Practice. Human Resource Management. (4th Ed) London:Kogan Page Ltd.

Attridge, M. (2009). Measuring and Managing Employee Work Engagement: A Review of the Research and Business Literature. Journal of Workplace Behavioral Health, 24(4), 383-398.

Avolio, B. J., Zhu, W., Koh, W., \& Bhatia, P. (2004). Transformational leadership and organizational commitment: Mediating role of psychological empowerment and moderating role of structural distance. Journal of Organizational Behavior. 25(8), 951 - 968.

Baird, K., \& Wang, H. (2010). Employee empowerment: extent of adoption and influential factors. Personnel Review, 39(5), 574-599.

Baron, R. M., \& Kenny, D. A. (1986). The moderator-mediator variable distinction in social psychological research: conceptual, strategic, and statistical considerations. Journal of Personality and Social Psychology, 51(6), 1173-82. Retrieved from http://www.ncbi.nlm.nih.gov/pubmed/3806354 
Barroso Castro, C., Villegas Periñan, M. M., \& Casillas Bueno, J. C. (2008). Transformational leadership and followers' attitudes: the mediating role of psychological empowerment. The International Journal of Human Resource Management, 19(10), 1842-1863.

Bechwati, N. N., \& Baalbaki, I. (2011). "The Power of One in Mindful Consumer Behavior", Advances in Consumer Research. 39(2011), 752753.

Bryman, A., \& Bell, E. (2007). Business Research Methods (2 ${ }^{\text {nd }}$ ed.).New York, NY: Oxford University Press.

Buitendach, J. H. D. W. (2005). Job insecurity, extrinsic and intrinsic job satisfaction and affective organisational commitment of maintenance workers in a parastatal. South African Journal of Business Management, 36(2), 27.

Bushra, F., Usman, A., \& Naveed, A. (2011). Effect of Transformational Leadership on Employees ' Job Satisfaction and Organizational Commitment in Banking Sector of Lahore ( Pakistan ).Journal of Business \& Social Science, 2(18), 261-268.

Cabrera, A., \& Cabrera, E. F. (2002). Knowledge-sharing Dilemmas*. Organization Studies, 23(5), 687-710.

Carless, S. A. (2004). Does psychological empowerment mediate the relationship between psychological climate and job satisfaction? Journal of Business and Psychology, 18(4), 405-425.

Castro, C. B., Periñan, M. M. V., \& Bueno, J. C. C. (2008). Transformational leadership and followers' attitudes: the mediating role of psychological empowerment. The International Journal of Human Resource Management, 19(10), 1842-1863.

Cohen, J. (1988). Statistical Power Analysis for the Behavioral Sciences. ( $2^{\text {nd }}$ ed.). Hillsdale, NJ: Lawrence Erlbaum.

Crawford, E. R., Lepine, J. A., \& Rich, B. L. (2010). Linking job demands and resources to employee engagement and burnout: A theoretical 
extension and meta-analytic test. Journal of Applied Psychology, 95(5), 834-848.

Danish, R. Q., \& Usman, A. (2010). Impact of Reward and Recognition on Job Satisfaction and Motivation: An Empirical Study from Pakistan. International Journal of Business and Management, 5(2001), 159-167.

Dartey-Baah, K., \& Amoako, G. K. (2011). Application of Frederick Herzberg's Two-Factor theory in assessing and understanding employee motivation at work: a Ghanaian Perspective. European Journal of Business and Management, 3(9), 1-8. Retrieved from http://iiste.org/Journals/index.php/EJBM/article/view/642

Dickson, K. E., Lorenz, A., \& Illinoisan, S. (2009). Psychological Empowerment and Job Satisfaction of Temporary and Part-Time Nonstandard Workers: A Preliminary Investigation. Journal of Behavioral \& Applied Management, 10(2), 166-192.

Elnaga, A. A., \& Imran, A. (2014). The Impact of Employee Empowerment on Job Satisfaction: Theoretical Study. American Journal of Research Communication, 2(1), 13-26.

Ewen, R. B., Smith, P. C., Hulin, C. L., \& Locke, E. A. (1966). An empirical test of the Herzberg two-factor theory. Journal of Applied Psychology, 50(6), 544-550.

Fernandez, S., \& Moldogaziev, T. (2013).Employee Empowerment, Employee Attitudes, and Performance: Testing a Causal Model. Public Administration Review, 73(3), 490-506.

Fornell, C., \& Larcker, D. F. (1981). Structural Equation Models with Unobservable Variables and Measurement Error: Algebra and Statistics. Journal of Marketing Research, 18(3), 382-388.

Fulford, M., \& Enz, C. A. (1995). The impact of empowerment on service employees. Journal of Managerial Issues, 7(2), 161-175.

George, D., \& Mallery, P. (2003). SPSS for Windows Step by Step: A Simple Guide and Reference, 11.0 Update. Boston, MA: Allyn \& Bacon. 
Gerstner, C. R., \& Day, D. V. (1997). Meta-analytic review of leadermember exchange theory: Correlates and construct issues. Journal of Applied Psychology, 82(6), 827-844.

Gokhan, T. N., \& Kuzey, C. (2019). Leadership , job satisfaction and performance links in private education institutes of Pakistan. International Journal of Productivity and Performance Management, 68 (2), 275-296.

Greasley, K., Bryman, A., Dainty, A., Price, A., Soetanto, R., \& King, N. (2005). Employee perceptions of empowerment. Employee Relations, 27(4), 354-368.

Hair, J. F., Black, W. C., Babin, B. J., \& Anderson, R. E. (2006). Multivariate Data Analysis (6 ${ }^{\text {th }}$ ed.). Englewood Cliffs, NJ: Prentice Hall.

Hair, J. F. J., Black, W. C., Babin, B. J., \& Anderson, R. E. (2009). Structural Equation Modeling Basics. In Multivariate Data Analysis (7th ed.). Englewood Cliffs, NJ: Prentice Hall.

Hanaysha, J., \& Tahir, P. R. (2016). Examining the Effects of Employee Empowerment, Teamwork, and Employee Training on Job Satisfaction. Procedia - Social and Behavioral Sciences, 219(2016), 272282.

Henseler, J., Dijkstra, T. K., Sarstedt, M., Ringle, C. M., Diamantopoulos, A., Straub, D. W., ... Calantone, R. J. (2014). Common beliefs and reality about PLS: Comments on Rönkkö and Evermann (2013). Organizational Research Methods, 17(2), 182-209.

Herzberg, F. (1959). The Motivation to Work. (2 ${ }^{\text {nd }}$ ed). New York: John Wiley.

Kundu, S. C., Kumar, S., \& Gahlawat, N. (2019). Empowering leadership and job performance: mediating role of psychological empowerment. Management Research Review, 42(5). 605-624.

Laschinger, H. K. S., Finegan, J., \& Shamian, J. (2002). The impact of workplace empowerment, organizational trust on staff nurses' work satisfaction and organizational commitment. Advances in Health Care Management, 26(3), 7-23. 
Laschinger, H. K. S., Finegan, J., Shamian, J., \& Wilk, P. (2004). A Longitudinal Analysis of the Impact of Workplace Empowerment on Staff Nurses' Work Satisfaction. Journal of Organizational Behavior, 25(4), 527-545.

Laschinger, H. (2008). Effect of Empowerment on Professional Practice Environments, Work Satisfaction, and Patient Care Quality. Journal of Nursing Care Quality, 23(4), 322-330.

Lee, Y.-M., \& Kim, B.-M. (2008). The mediator effect of empowerment in relationship between transformational leadership and organizational commitment. Taehan Kanho Hakhoe Chi, 38(4), 603611.

Locke, E. A. (1976). The nature and causes of job satisfaction. In Handbook of industrial and organizational psychology, M. D. Dunnette (Ed.) (pp. 1297-1343). Chicago, IL: Rand McNally.

Loi, R., Yang, J., \& Diefendorff, J. M. (2009). Four-factor justice and daily job satisfaction: a multilevel investigation. The Journal of Applied Psychology, 94(3), 770-781.

Macey, W. H., \& Schneider, B. (2008). The Meaning of Employee Engagement. Industrial and Organizational Psychology, 1(January), 330 .

Michael Ba, B.-G. (2015). Understanding leadership and empowerment in the workplace. European Scientific Journal, 11(35). Retrieved fromhttps://eujournal.org/index.php/esj/article/viewFile/6801/6528

Nel, T., Stander, M. W., \& Latif, J. (2015). Investigating positive leadership, psychological empowerment, work engagement and satisfaction with life in a chemical industry. SA Journal of Industrial Psychology, 41(1), 1-13.

Oluwaseun, I. S. (2016). The Effect of Employee Empowerment and Job Satisfaction on Intention to Stay in Nigeria Banking Industry $\square$ : A Case Study of Guaranty Trust Bank (Masters Thesis).Retrieved From Eastern Mediterranean University Institutional Repository.URL: http://i- 
rep.emu.edu.tr:8080/xmlui/bitstream/handle/11129/2872/oluwaseu nibrahim.pdf?sequence $=1$

Pelit, E., Öztürk, Y., \& Arslantürk, Y. (2011). The effects of employee empowerment on employee job satisfaction: A study on hotels in Turkey. International Journal of Contemporary Hospitality Management, 23(6), 784-802.

Pieterse, A. N., van Knippenberg, D., Schippers, M., \& Stam, D. (2010). Transformational and transactional leadership and innovative behavior: The moderating role of psychological empowerment. Journal of Organizational Behavior, 31(4), 609-623.

Pigg, K. E. (2002). Three Faces of Empowerment: Expanding the Theory of Empowerment in Community Development. Journal of the Community Development Society, 33(1), 107-123.

Porter, L. W., \& Lawler, E. E. (1968). Managerial attitudes and performance. Homewood, IL: Dorsey.

Qing, M., Asif, M., Hussain, A., \& Jameel, A. (2019). Exploring the impact of ethical leadership on job satisfaction and organizational commitment in public sector organizations $\square$ : the mediating role of psychological empowerment. Review of Managerial Science, 13(1), 1-28.

Quinn, R. E., \& Spreitzer, G. M. (1997). The road to empowerment: Seven questions every leader should consider. Organizational Dynamics, 26(2), 37-49.

Rad, A. M. M., \& Yarmohammadian, M. H. (2006). A study of relationship between managers' leadership style and employees' job satisfaction. International Journal of Health Care Quality Assurance Incorporating Leadership in Health Services, 19(2-3), xi-xxviii.

Rajotte, C. A. (1996). Empowerment as a leadership theory. Kans Nurse, 71(1), 1.

Reams, R. (2013). Online Social Presence ( OSP ) In E-Tailing $\square$ : Construct Development And Testing.(Doctoral Thesis). Kennesaw State University, GA. 
Saeed, R., Mussawar, S., Lodhi, R. N., Iqbal, A., Nayab, H. H., \& Yaseen, S. (2013). Factors Affecting the Performance of Employees at Work Place in the Banking Sector of Pakistan. Middle-East Journal of Scientific Research, 17(9), 1200-1208.

Saleem, H. (2015). The Impact of Leadership Styles on Job Satisfaction and Mediating Role of Perceived Organizational Politics. Procedia Social and Behavioral Sciences, 172, 563-569.

Salek, S., \& Khoeini, F. (2016). Studying the Relation between the Transformational Leadership and Employees Empowerment (Case Study of Bank Passargad of Iran). Modern Applied Science, 11(2), 61.

Santos, J. R. A. (1999). Cronbach's alpha: A tool for assessing the reliability of scales. Journal of Extension, 37(2), 1-5. Retrieved from http://www.joe.org/joe/1999april/tt3.php?ref

Sekaran, U. (2000). Research Methods for Business: A Skill Business Approach. New York, NY: John Wiley \& Sons.

Shahid, H., Rehman, R. U., Niazi, G. S. K., \& Raoof, A. (2010). Efficiencies comparison of Islamic and conventional banks of Pakistan. International Research Journal of Finance and Economics, 49(9), 24-42.

Shaista, M., Muhammad, H., Muhammad, A., \& Syed, G. A. (2019). The influence of structural empowerment and resonant leadership on job satisfaction of registered nurses at public hospital of lahore pakistan. International Journal of Advancements in Research $\mathcal{E}$ Technology, 8(1), 15-26.

Singh, S. K., \& Singh, A. P. (2019). Interplay of organizational justice, psychological empowerment, organizational citizenship behavior, and job satisfaction in the context of circular economy. Management Decision, 57(4), 937-952.

Sohail, N., Iqbal, J., Tariq, H., \& Mumtaz, R. (2013). Determinants of Commercial Banks Profitability: Panel Data Evidence from Pakistan. Research Journal of Finance and Accounting, 4(10), 2222-2847. 
Sternberg, L. E. (1992). Empowerment: Trust vs. control. Cornell Hotel and Restaurant Administration Quarterly, 33(1), 69-72.

Ugboro, I. O., \& Obeng, K. (2000). Top management leadership, employee empowerment, job satisfaction, and customer satisfaction in TQM organizations: an empirical study. Journal of Quality Management, 5(2), 247-272.

Wang, P., \& Walumbwa, F. O. (2007). Family-friendly programs, organizational commitment, and work withdrawal: The moderating role of transformational leadership. Personnel Psychology, 60(2), 397-427.

Yong, J., Peiwei, L., Jingying, W., \& Hui, L. (2019). Relationships between kindergarten teachers $\hat{a} €^{\mathrm{tm}}$ empowerment, job relationships between kindergarten teachers' empowerment, job satisfaction, and organizational climate: A Chinese model. Journal of Research in Childhood Education, 2019(1), 1-14. 